Article

\title{
Electrophoretic Deposition as a New Bioactive Glass Coating Process for Orthodontic Stainless Steel
}

\author{
Kyotaro Kawaguchi ${ }^{1}$, Masahiro Iijima ${ }^{1, *}$, Kazuhiko Endo ${ }^{2}$ and Itaru Mizoguchi ${ }^{1}$ \\ 1 Division of Orthodontics and Dentofacial Orthopedics, School of Dentistry, \\ Health Sciences University of Hokkaido, Hokkaido 061-0293, Japan; \\ kawaguchi320@hoku-iryo-u.ac.jp (K.K.); mizo@hoku-iryo-u.ac.jp (I.M.) \\ 2 Division of Biomaterials and Bioengineering, School of Dentistry, Health Sciences University of Hokkaido, \\ 1757 Kanazawa, Ishikari-Tobetsu, Hokkaido 061-0293, Japan; endo@hoku-iryo-u.ac.jp \\ * Correspondence: iijima@hoku-iryo-u.ac.jp; Tel.: +81-133-23-2977
}

Academic Editor: Saber AminYavari

Received: 6 October 2017; Accepted: 10 November 2017; Published: 13 November 2017

\begin{abstract}
This study investigated the surface modification of orthodontic stainless steel using electrophoretic deposition (EPD) of bioactive glass (BG). The BG coatings were characterized by spectrophotometry, scanning electron microscopy with energy dispersive $\mathrm{X}$-ray spectrometry, and $X$-ray diffraction. The frictional properties were investigated using a progressive load scratch test. The remineralization ability of the etched dental enamel was studied according to the time-dependent mechanical properties of the enamel using a nano-indentation test. The EPD process using alternating current produced higher values in both reflectance and lightness. Additionally, the BG coating was thinner than that prepared using direct current, and was completely amorphous. All of the BG coatings displayed good interfacial adhesion, and $\mathrm{Si}$ and $\mathrm{O}$ were the major components. Most BG-coated specimens produced slightly higher frictional forces compared with non-coated specimens. The hardness and elastic modulus of etched enamel specimens immersed with most BG-coated specimens recovered significantly with increasing immersion time compared with the non-coated specimen, and significant acid-neutralization was observed for the BG-coated specimens. The surface modification technique using EPD and BG coating on orthodontic stainless steel may assist the development of new non-cytotoxic orthodontic metallic appliances having satisfactory appearance and remineralization ability.
\end{abstract}

Keywords: electrophoretic deposition; enamel remineralization; bioactive glass; spectrophotometry; nanoindentation

\section{Introduction}

Many orthodontic materials are formed from metals, which typically have superior mechanical properties compared with other materials. However, there are aesthetic issues with metal orthodontic materials [1]. More aesthetically attractive orthodontic materials are desirable, especially for adult patients. Aesthetic brackets made from ceramics and plastics have been widely used in clinical orthodontics [2,3]. Unfortunately, ceramic brackets have shortcomings stemming from their brittle nature, e.g., occasional fracture when tying the ligature and fracture from archwire forces, along with tooth wear during treatment and enamel fracture at debonding [1,4]. Plastic brackets also have deficiencies, such as a tendency to discolor, wear and creep due to their poor mechanical properties $[1,5]$. To overcome these issues, glass fiber-reinforced polymer wires have been investigated [6-9] but have yet to be used widely because of their brittleness and inability to withstand sufficient force [6-8]. Recently, coated archwires, including metal wires coated with polymers and rhodium-plated wires, have been developed [10-15]. These are preferred by many patients and orthodontists because of their 
improved aesthetic qualities. However, polymer-coated wire loses a significant amount of its coating layer when used in the areas of archwire engagement [11,12], which affects frictional properties and bacterial adhesion $[13,15]$.

Acid-etching of enamel surfaces for bracket bonding procedures has been accepted in modern clinical orthodontics since the direct bonding of orthodontic brackets to enamel was introduced in the mid-1960s [16,17]. The enamel surface around bonded brackets etched with phosphoric acid is more susceptible to demineralization because the areas stagnate with plaque, making tooth-cleaning more difficult and limiting the efficacy of natural self-cleaning mechanisms. Additionally, the mechanical properties of the enamel surface region decreased after bracket bonding with the etch-and-rinse adhesive system [18], and irreversible alteration of the enamel might increase the risk of enamel micro-cracks forming during debonding procedures. Therefore, further demineralization of the enamel after bracket bonding should be prevented and, ideally, remineralization should be enhanced.

One reasonable way to enhance the remineralization of tooth surfaces is to increase the calcium or fluoride concentrations of oral fluids $[19,20]$. Various bioactive glass (BG) have been investigated since the first ones were reported by Hench et al. (1971) [21]. These studies have included their osteo-inductive behavior, ability to bond to both soft and hard tissues, the capacity of the glass to release ions $(\mathrm{Ca}, \mathrm{Na}, \mathrm{Si})$, and the ability to form a hydroxyapatite layer [22-25]. More recently, attention has focused on their modification to further enhance osteogenic behavior, or on further compositional changes to introduce additional multifunctional properties such as antimicrobial activity [26]. If the surface of the metallic orthodontic materials can be modified with a BG, it may help to prevent the demineralization of tooth surfaces surrounding brackets and enhance remineralization after bracket debonding; these features are attractive in the clinical orthodontic setting.

Electrophoretic deposition (EPD) is a simple, rapid, and versatile coating technique, whereby colloidal particles suspended in a liquid medium migrate under the influence of an appropriate electric field and are deposited onto an electrode, leading to film formation and coatings with high microstructural homogeneity and tailored thickness [27,28]. Among the different techniques used for surface modification in the biomedical field, EPD is particularly attractive because it is does not require expensive equipment and can be used with colloidal BG particles to form complex-shaped orthodontic materials.

In this article, BG particles were deposited onto orthodontic stainless steel disks by an EPD process under various conditions, and the BG coating was characterized esthetically, morphologically, and compositionally using various methods. Additionally, the effects of the BG coating on the remineralization ability of etched dental enamel and frictional properties were investigated.

\section{Materials and Methods}

\subsection{Materials}

Mechanically polished stainless steel (SUS316) disk specimens (diameter: $14 \mathrm{~mm}$; thickness: $2 \mathrm{~mm}$; Nogata Denki Kogyo, Tokyo, Japan) were purchased and cleaned ultrasonically and subjected to the BG coating process. Non-coated specimens served as a control.

The $\mathrm{BG}\left(45.0 \% \mathrm{SiO}_{2}+24.5 \% \mathrm{Na}_{2} \mathrm{O}+24.5 \% \mathrm{CaO}+6.0 \% \mathrm{P}_{2} \mathrm{O}_{5}\right)$ was prepared by melting the raw materials in a platinum crucible at $1550{ }^{\circ} \mathrm{C}$ for $90 \mathrm{~min}$ using an electrically heated furnace (model SSFT-1520; Yamada Denki, Tokyo, Japan). The molten glass was rapidly quenched by malleating (rolling) between two stainless steel plates of 10-mm thickness. After cooling overnight, the glass was ground for $2 \mathrm{~min}$ in a vibrational rod mill (model TI-200; CMT Co., Fukushima, Japan) to yield a particle diameter of ca. $100 \mu \mathrm{m}$. The powders were further milled using a high-pressure gas-milling apparatus (Nano Jetmizer; Aishin Nano Technologies, Saitama, Japan) under a grinding pressure of 1.4 MPa to provide particles with a median diameter (D50) of $1.98 \mu \mathrm{m}$. Analysis of the BG by X-ray diffraction (XRD) confirmed its amorphous structure. 


\subsection{EPD Process}

Suspensions containing $20 \mathrm{~g} / \mathrm{L}$ of BG were prepared in $100 \mathrm{~mL}$ of distilled water by dispersing the particles via magnetic stirring and sonication (model UD-100; Tomy Seiko, Tokyo, Japan) for $600 \mathrm{~s}$ (The BG in distilled water was $0.2 \mathrm{~g} / \mathrm{mL}$ ). The stainless-steel specimens were encapsulated in a silicone impression material except for an exposed deposition area $14 \mathrm{~mm}$ in diameter. The EPD cell included two parallel stainless steel disk specimens as the deposition and counter electrodes; the distance between the electrodes was maintained at $3 \mathrm{~mm}$. The coating was deposited using direct current (DC) or 1-kHz sine-wave alternating current (AC). Constant voltages (10 and $15 \mathrm{~V})$ were applied and the deposition time was $10 \mathrm{~min}$ for all conditions. All measured $\mathrm{pH}$ values of the mixed suspension were $\mathrm{pH} 12.0 \pm 0.1$. After deposition, a coated specimen was gently removed from the suspension and dried at room temperature for $24 \mathrm{~h}$ before further characterization (Figure 1).

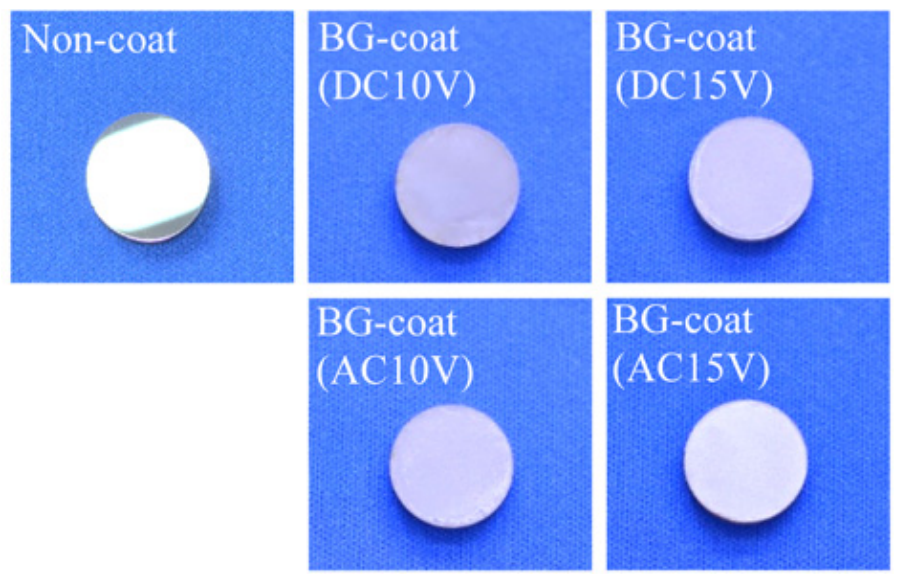

Figure 1. Photomicrographs of the non- and bioactive glass (BG)-coated specimens.

\subsection{Color Measurements}

The color of each specimen was measured using a spectrophotometer (model UV-2600; Shimadzu, Kyoto, Japan) with an integrated sphere (model ISR-2600 Plus; Shimadzu). Diffuse reflectance measurements were performed in the range of 350-800 nm in 1-nm steps. Color was measured according to the Commission International de L'Eclairage (CIE) $L^{*} a^{*} b^{*}$ color system [29] $(n=5)$, which has a lightness scale, $L^{*}$, and two opponent color axes, $a^{*}$ and $b^{*}$. The redness and greenness are represented by the $a^{*}$ values and the yellowness and blueness are represented by the $b^{*}$ values.

\subsection{Characterization of the Coatings}

The surfaces of coated specimens were analyzed using XRD (model Rint-2500; Rigaku Corp., Tokyo, Japan) via a parallel-beam method using $\mathrm{Cu}-\mathrm{K} \alpha$ radiation $(40 \mathrm{kV}$; tube current: $100 \mathrm{~mA})$. Representative specimens were analyzed over the $2 \theta$ range from 10 to $60^{\circ}$ using a step size of $0.02^{\circ}$ and a scan speed of $0.25^{\circ} / \mathrm{min}$. The XRD patterns were obtained at $25^{\circ} \mathrm{C}$ and analyzed qualitatively using PDXL2 software (Rigaku) based on the International Center for Diffraction Data (ICDD) database for phase identification and quantification.

To observe the coated layers and analyze their compositions on the cross-sectioned surface, specimens were encapsulated in an epoxy resin (Epofix; Struers, Copenhagen, Denmark) and cross-sectioned with a slow-speed, water-cooled diamond saw (Isomet; Buehler, Lake Bluff, IL, USA), then ground and polished using a series of silicon carbide abrasive papers and a final slurry of $0.05-\mu \mathrm{m}$ alumina particles. All specimens were sputter-coated with pure gold for scanning electron microscopy (SEM) evaluation (model SSX-550; Shimadzu); the SEM was operated at $15 \mathrm{kV}$. The composition of a coated specimen was determined by energy-dispersive X-ray spectroscopy (EDS) at a working distance of $15 \mathrm{~mm}$ and a data acquisition time of $300 \mathrm{~s}$. 


\subsection{Mechanical Properties of the Coatings}

The external surfaces of the specimens were investigated with a nano-indentation apparatus (model ENT-1100a; Elionix, Tokyo, Japan). The specimens were fixed to the specimen stage with adhesive resin (Superbond Orthomite; Sun Medical, Shiga, Japan). Nano-indentation testing was carried out at $28{ }^{\circ} \mathrm{C}$ using a Berkovich indenter with a $10-\mathrm{mN}$ peak load for ca. $1000 \mathrm{~nm}$ depth analysis $(n=10)$. Linear extrapolation methods (ISO Standard 14577) were used for the unloading curve between $95 \%$ and $70 \%$ of the maximum test force to calculate the elastic modulus [30-33]. The hardness and elastic modulus of the buccal enamel surfaces were calculated using the software bundled with the nano-indentation apparatus.

\subsection{Frictional Properties Measured by the Progressive Load Scratch Test}

A microtribometer (model CETR-UMT-2; Bruker, Billerica, MA, USA) was used to characterize the frictional properties by the progressive load scratch test. A diamond stylus having a $12.5-\mu \mathrm{m}$ tip radius was moved $5 \mathrm{~mm}$ over a specimen surface with linearly increasing normal load ( 0.5 to $20 \mathrm{gf}$ ) at a constant speed of $0.016 \mathrm{~mm} / \mathrm{s}$, and the value of the friction coefficient was obtained $(n=5)$.

\subsection{Acid-Neutralizing Ability}

To estimate the acid-neutralizing ability, disk specimens were immersed in individual plastic vials containing $10 \mathrm{~mL}$ of acetic acid solution $(\mathrm{pH}=4.5)$ at $37^{\circ} \mathrm{C}$. The time-dependent changes in the $\mathrm{pH}$ of the solutions were measured (model SI600; Sentron, Roden, The Netherlands) with a micro-pH electrode (model 9070-008; Sentron) over $24 \mathrm{~h}(n=5)$.

\subsection{Enamel Remineralization Ability and Changes in the Mechanical Properties}

A total of 38 human non-carious premolars, obtained by extraction from patients undergoing orthodontic treatment, were cut with a slow-speed, water-cooled diamond saw (Isomet; Buehler, Lake Bluff, IL, USA) so that they were divided into mesial and distal halves; the sectioned specimens were then encapsulated in epoxy resin (Epofix; Struers, Copenhagen, Denmark). This in vitro study was approved by the ethics committee of the Health Sciences University of Hokkaido. After $24 \mathrm{~h}$, the specimens were lightly ground with 600-grit sandpaper, and polished progressively using diamond suspensions with particle sizes of 3,1 , and $0.25 \mu \mathrm{m}$ to obtain a surface suitable for nano-indentation. This polishing procedure removed approximately $200 \mu \mathrm{m}$ of the tooth surface; a total of 75 polished-surface enamel specimens with an approximate area of $4 \times 4 \mathrm{~mm}^{2}$ were finally obtained. The specimens were divided into five groups of 15 specimens. Embedded human enamel specimens were etched with 35\% phosphoric acid gel (Transbond XT Etching Gel; 3M Unitek, Monrovia, CA, USA) for $15 \mathrm{~s}$, washed for $20 \mathrm{~s}$, and dried in an air stream. Each etched enamel and disk specimen was fixed on a specimen stage and then immersed in a plastic vial containing $10 \mathrm{~mL}$ of artificial saliva at $37^{\circ} \mathrm{C}$ for 3 months, with the solution changed weekly. Nano-indentation testing of the enamel surfaces was carried out at $28^{\circ} \mathrm{C}$ (model ENT-1100a; Elionix) using two different loads (10 and $100 \mathrm{mN}$ ), before and after etching and during immersion periods. The hardness and elastic modulus of the buccal enamel surfaces were calculated.

\subsection{Cytocompatibility}

Mouse L929 fibroblast cells were seeded at a density of 5000 cells $/ \mathrm{cm}^{2}$ in 96 -well plates and incubated in MEM $\alpha$ (Wako Pure Chemical, Osaka, Japan) containing $5 \%$ fetal bovine serum (ICN Biomedicals, Irvine, CA, USA) for $36 \mathrm{~h}$ at $37^{\circ} \mathrm{C}$ with $5 \% \mathrm{CO}_{2}$. Each disk specimen was immersed into $10 \mathrm{~mL}$ of culture solution for $24 \mathrm{~h}$ and then $100 \mu \mathrm{L}$ of the solution was added to each 96-well plate, followed by $24 \mathrm{~h}$ incubation. Finally, the absorbance of each well at $450 \mathrm{~nm}$ was recorded using a microplate reader (model Infinite F200; Männedorf, Switzerland) $(n=10)$. 


\subsection{Statistical Analyses}

Statistical analyses were performed using the PASW Statistics software (ver. 18.0 J for Windows; IBM, Armonk, NY, USA). The mean values with standard deviations obtained for the various experiments in this study were compared using one-way analysis of variance (ANOVA) followed by Tukey's test. For all statistical tests, significance was predetermined at $p<0.05$.

\section{Results}

\subsection{Color Measurements}

Figure 2 shows the changes in representative diffuse reflectance curves for the specimens. The lightness $\left(L^{*}\right)$ and two opponent color $\left(a^{*}, b^{*}\right)$ values are summarized in Table 1 . The reflectance values $(\%)$ increased with increasing wavelength for all specimens. Non-coated specimens showed significantly higher reflectance values in the $350-800 \mathrm{~nm}$ range and $L^{*}$, due to the polished bright surface acting as a mirror. Among the BG-coated specimens, the one prepared using AC $15 \mathrm{~V}$ showed the highest values for both reflectance in the 350-800 nm range and $L^{*}$, followed by specimens coated at DC $15 \mathrm{~V}, \mathrm{AC} 10 \mathrm{~V}$, and DC $10 \mathrm{~V}$. The specimens coated at higher voltage (15 V) showed significantly higher reflectance and $L^{*}$ values than those coated at lower voltage $(10 \mathrm{~V})$. Similar $a^{*}$ and $b^{*}$ values were obtained for most BG-coated specimens.

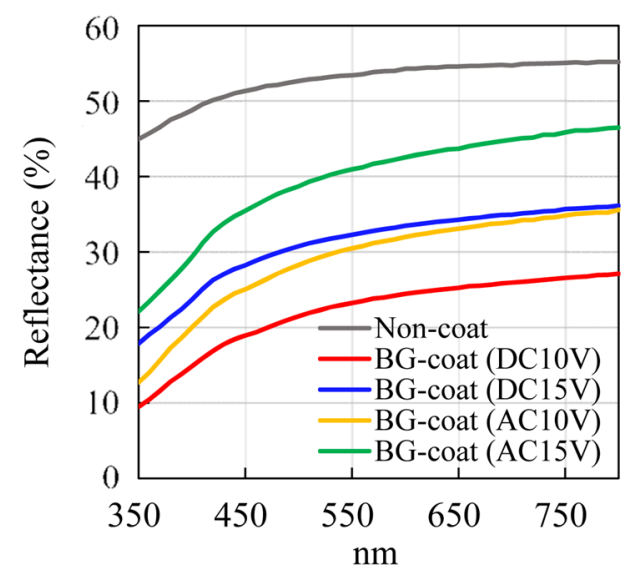

Figure 2. Diffuse reflectance curves of the various specimens.

Table 1. Commission International de L'clairage (CJE) lightness $\left(L^{*}\right)$ and color $\left(a^{*}, b^{*}\right)$ values for the specimens.

\begin{tabular}{|c|c|c|c|c|c|c|c|c|c|c|c|}
\hline \multirow[t]{2}{*}{ Coordinate } & \multicolumn{2}{|c|}{ Non-Coat } & \multicolumn{2}{|c|}{$\begin{array}{l}\text { BG-Coat } \\
\text { (DC } 10 \mathrm{~V})\end{array}$} & \multicolumn{2}{|c|}{$\begin{array}{c}\text { BG-Coat } \\
\text { (DC } 15 \mathrm{~V})\end{array}$} & \multicolumn{2}{|c|}{$\begin{array}{l}\text { BG-Coat } \\
(\mathrm{AC} 10 \mathrm{~V})\end{array}$} & \multicolumn{2}{|c|}{$\begin{array}{c}\text { BG-Coat } \\
\text { (AC 15 V) }\end{array}$} & \multirow[t]{2}{*}{$p$ Value } \\
\hline & mean & S.D. & mean & S.D. & mean & S.D. & mean & S.D. & mean & S.D. & \\
\hline$L^{*}$ & $78.02^{a}$ & 0.14 & $54.88^{a}$ & 0.34 & $63.79^{c}$ & 0.14 & $61.83^{\mathrm{d}}$ & 0.36 & $70.42^{\mathrm{e}}$ & 0.71 & 0.000 \\
\hline$a^{*}$ & $-0.12^{\mathrm{a}}$ & 0.03 & $-0.50^{b}$ & 0.05 & $-0.48^{b}$ & 0.10 & $-0.48^{b}$ & 0.02 & $-0.41^{b}$ & 0.11 & 0.000 \\
\hline$b^{*}$ & $2.31^{\mathrm{a}}$ & 0.10 & $7.89^{b}$ & 0.30 & $6.12^{c}$ & 0.65 & $8.12^{b}$ & 0.10 & $6.70^{c}$ & 0.26 & 0.000 \\
\hline
\end{tabular}

Notes: Values are mean and standard deviation (S.D.), $n=7$. One-way ANOVA followed by Tukey-Kramer multiple range test. ${ }^{\mathrm{a}-\mathrm{e}}$ Idential letters indicate that mean values were not significantly different $(p<0.05)$.

\subsection{Crystal Structures, Morphological Features, and Compositions of the Coating Layers}

Figure 3 displays representative XRD spectra of non- and BG-coated specimens. Weak broad feature at around $32^{\circ}$ was obtained for the BG-coated specimen (AC 15V) because of the amorphous structure. On the other hand, two peaks at $2 \theta=43.5$ and $51.0^{\circ}$ associated with the austenite $(\gamma-\mathrm{Fe})$ phase (ICDD PDF 01-071-4649) were observed for the BG-coated specimen (DC 15V), while the broad feature at around $32^{\circ}$ was observed. 


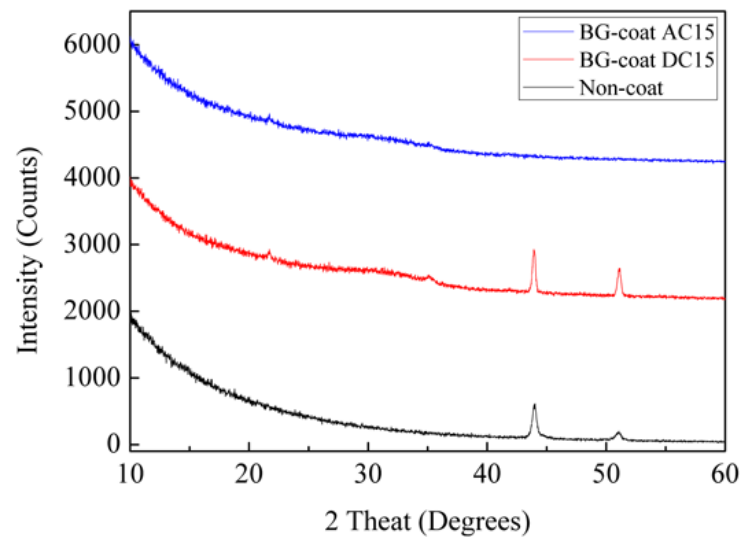

Figure 3. Representative X-ray diffraction (XRD) spectra of the non- and BG-coated specimens.

Figure 4 shows SEM photomicrographs and qualitative compositional maps obtained by EDS of BG-coated cross-sectional specimens. The thickness of the BG coating layers formed on the disk surfaces was ca. 1.0-4.0 $\mu \mathrm{m}$ and the specimens coated at higher voltage $(15 \mathrm{~V})$ tended to have thicker BG coating layers than those coated at lower voltage $(10 \mathrm{~V})$. Additionally, the thickness of the BG coating layers were similar in both specimens coated with AC and DC. Good interfacial adhesion was observed between all BG coating layers and the bulk materials. Si and $\mathrm{O}$, the major components of BG, were enriched in all of the coating layers.
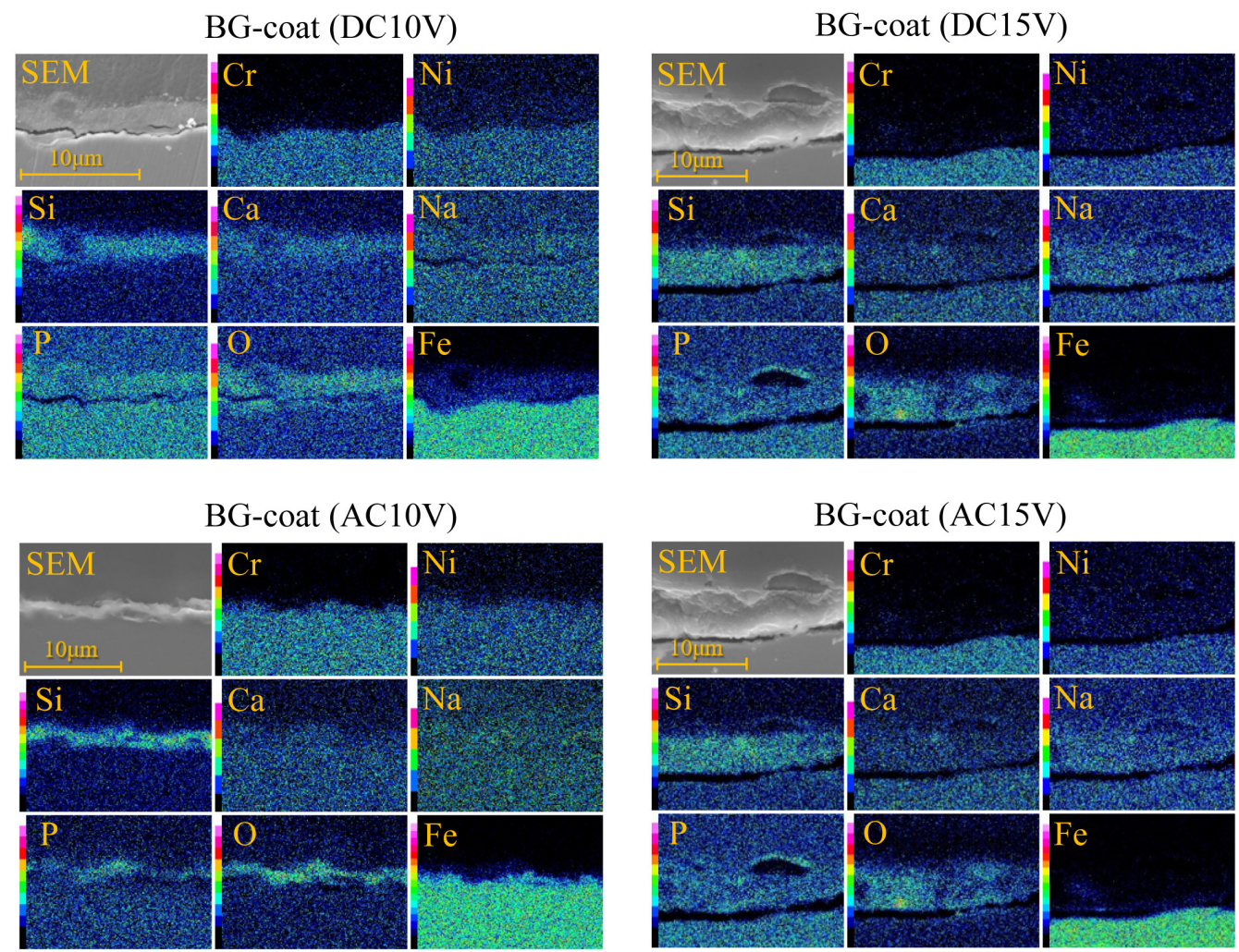

Figure 4. Scanning electron microscopy (SEM) photomicrographs and qualitative compositional maps obtained by energy-dispersive X-ray spectroscopy (EDS) of cross-sections of the BG-coated specimens. 


\subsection{Evaluation of the Mechanical Properties of the Coating Layers by Nanoindentation}

Table 2 summarizes the mechanical properties of surface regions for non- and BG-coated specimens. The hardness and elastic modulus of the BG layers were significantly lower than those of the non-coated specimen. The specimens coated at higher voltage $(15 \mathrm{~V})$ showed significantly higher the hardness and elastic modulus of the BG layers than those coated at lower voltage (10 V). The elastic modulus of the BG layers formed by AC were significantly higher than those for the BG layers formed by DC.

Table 2. Mechanical properties of the non- and bioactive glass (BG)-coated specimens.

\begin{tabular}{|c|c|c|c|c|c|c|c|c|c|c|c|}
\hline \multirow{2}{*}{ Mechanical Properties } & \multicolumn{2}{|c|}{ Non-Coat } & \multicolumn{2}{|c|}{$\begin{array}{c}\text { BG-Coat } \\
\text { (DC 10 V) }\end{array}$} & \multicolumn{2}{|c|}{$\begin{array}{c}\text { BG-Coat } \\
\text { (DC 15 V) }\end{array}$} & \multicolumn{2}{|c|}{$\begin{array}{l}\text { BG-Coat } \\
\text { (AC } 10 \mathrm{~V} \text { ) }\end{array}$} & \multicolumn{2}{|c|}{$\begin{array}{l}\text { BG-Coat } \\
\text { (AC 15 V) }\end{array}$} & \multirow{2}{*}{$p$ Value } \\
\hline & mean & S.D. & mean & S.D. & mean & S.D. & mean & S.D. & mean & S.D. & \\
\hline Hardness (GPa) & $6.11^{\mathrm{a}}$ & 0.22 & $0.49^{a}$ & 0.10 & $1.99^{c}$ & 0.52 & $0.85^{\mathrm{b}}$ & 0.48 & $1.98^{\mathrm{c}}$ & 0.73 & 0.000 \\
\hline Elastic modulus (GPa) & $192.46^{\mathrm{a}}$ & 4.96 & $70.47^{\mathrm{b}}$ & 23.22 & $109.12^{\mathrm{c}}$ & 23.39 & $84.32^{b c}$ & 15.28 & $128.5^{\mathrm{d}}$ & 27.65 & 0.000 \\
\hline
\end{tabular}

Notes: Values are mean and standard deviation (S.D.), $n=7$; One-way ANO VA followed by Tukey-Kramer multiple range test. Identical letters indicate that mean values were not significantly different $(p<0.05)$.

\subsection{Frictional Properties Measured by the Progressive Load Scratch Test}

Figure 5 shows the change in representative frictional force obtained by the progressive load scratch test. The BG-coated specimens (DC $15 \mathrm{~V}$ ) showed significantly higher frictional force than the other specimens when measured over $5 \mathrm{~mm}$. Over approximately the first $4 \mathrm{~mm}$ of the measurement distance, the other BG-coated specimens displayed slightly higher frictional force than the non-coated specimen.

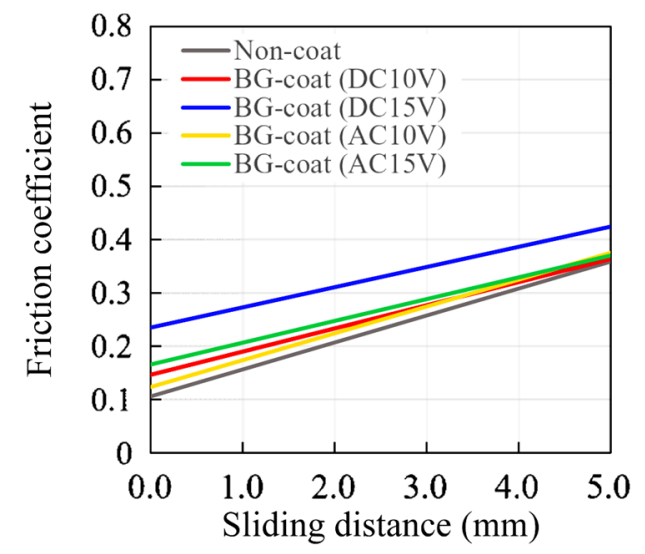

Figure 5. Frictional forces obtained by the progressive load scratch test.

\subsection{Analysis of Acid-Neutralizing Ability}

Figure 6 shows the time-dependent changes in the $\mathrm{pH}$ of the solutions as an indication of the acid-neutralizing ability. Immersion of BG-coated specimens in acetic acid solution caused an increase in the $\mathrm{pH}$, and the acid-neutralizing ability increased with increasing output voltage. 


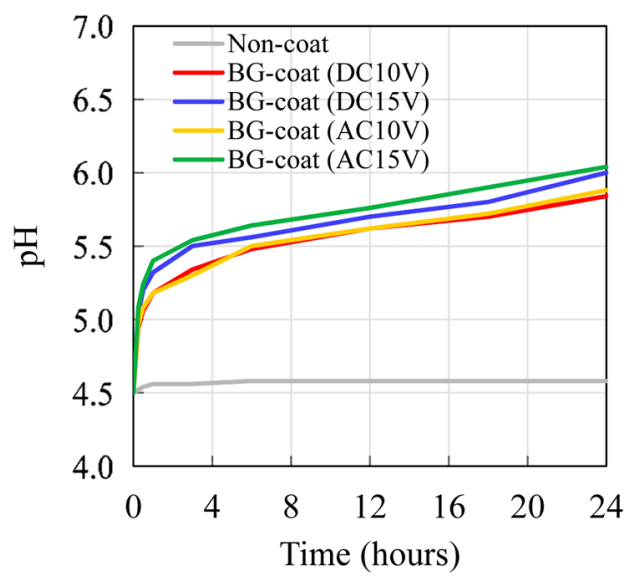

Figure 6. Time-dependent changes in the $\mathrm{pH}$ of the solutions as an indication of acid neutralizing ability.

\subsection{Enamel Remineralization Ability in Artificial Saliva and Mechanical Property Changes Determined by Nanoindentation}

Figures 7 and 8 show the mean hardness and elastic modulus values of the enamel surface before and after etching and during the 3 months of immersion. There was no significant difference in the hardness or elastic modulus between the groups before and immediately after etching. Phosphoric acid etching markedly decreased the hardness and elastic modulus of the enamel surfaces. The hardness and elastic modulus of the enamels of BG-coated specimens increased gradually with increasing immersion time. The recovery of the mechanical properties of a specimen immersed with a non-coated specimen was unremarkable. However, the hardness and elastic modulus of etched enamel specimens immersed with most BG-coated specimens recovered significantly compared with a non-coated specimen. Similar behavior was observed for both load conditions (10 and $100 \mathrm{mN})$.
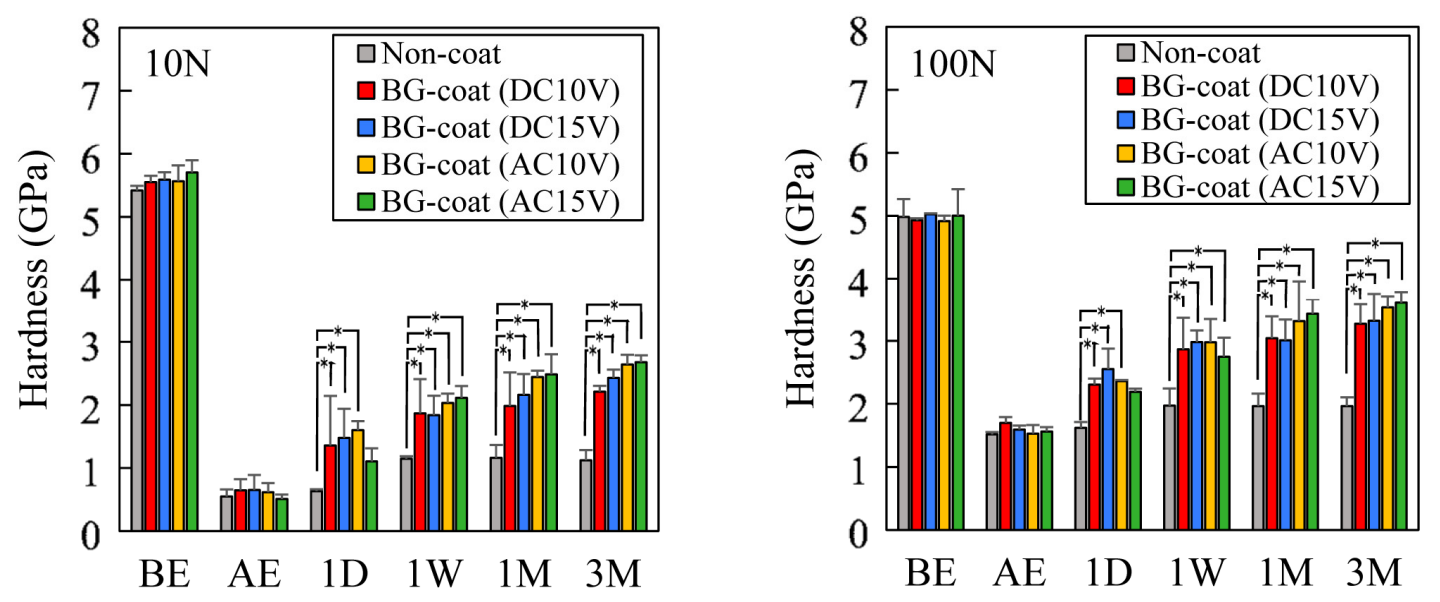

Figure 7. Mean hardness values of the enamel surface before and after etching, and during the 3-month immersion period. $\mathrm{BE}$, before etching; $\mathrm{AE}$, after etching; $1 \mathrm{D}, 1$-day immersion; 1W, 1-week immersion; $1 \mathrm{M}, 1$-month immersion; 3M, 3-month immersion. 

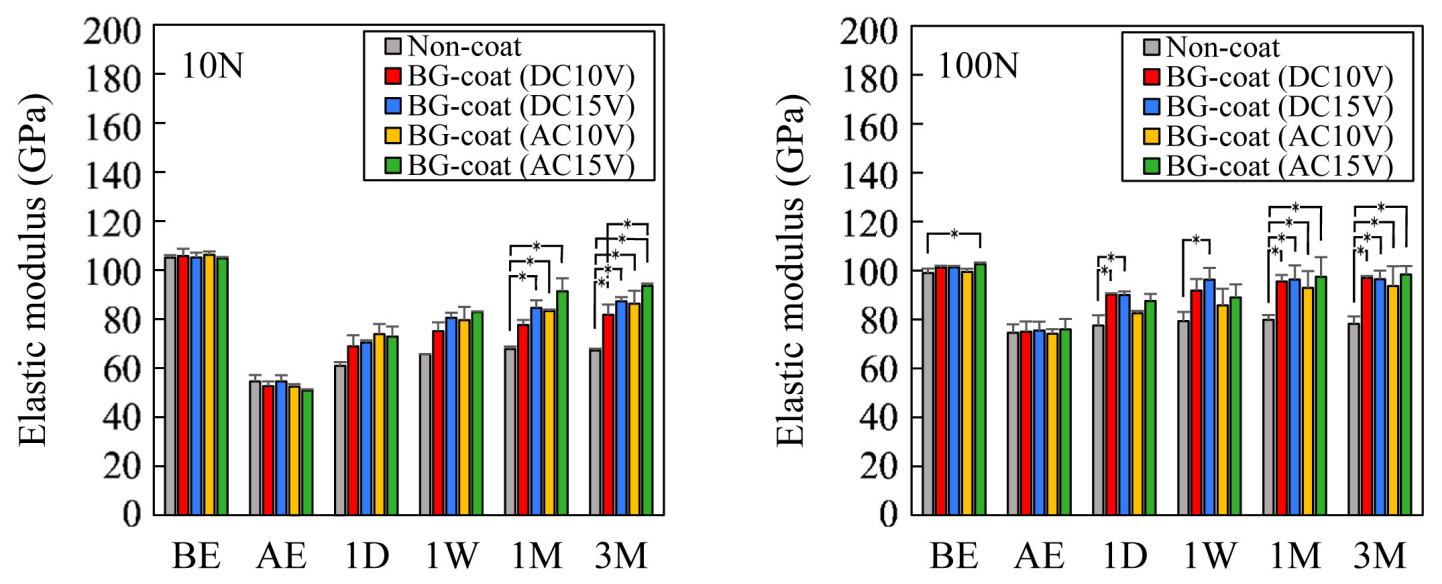

Figure 8. Mean elastic modulus values of the enamel surface before and after etching, and during the 3-month immersion period. BE, before etching; AE, after etching; 1D, 1-day immersion; 1W, 1-week immersion; 1M, 1-month immersion; 3M, 3-month immersion.

\subsection{Cytocompatibility Assays}

Figure 9 shows the absorbance at $450 \mathrm{~nm}$ as a function of the L929 fibroblast cell number at $36 \mathrm{~h}$. No significant difference was noted in the mean fibroblast cell growth for $36 \mathrm{~h}$, which indicated that the BG coatings were not cytotoxic.

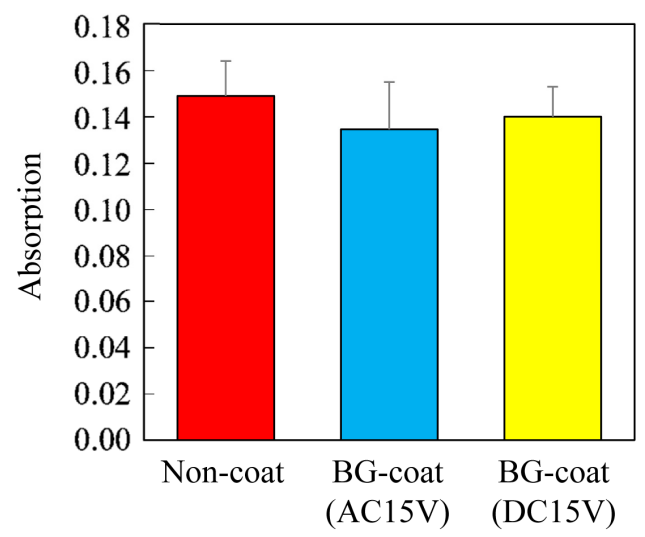

Figure 9. Absorbance at $450 \mathrm{nrn}$ as a function of the L929 fibroblast cell number at $36 \mathrm{~h}$.

\section{Discussion}

In the present study, thin BG coating layers with a milky-white appearance were formed on mechanically polished stainless steel specimens using an EPD process with a BG suspension and this is the first study that has investigate the esthetic performance of the BG coating. Quantitative color measurements showed that the EPD process using AC at $15 \mathrm{~V}$ produced higher values for both the reflectance (\%) in the range of 350-800 $\mathrm{nm}$ and $L^{*}$ (mean value: 70.42). The range of $L^{*}$ values measured for the BG coating layers in the present study (54.88 to 70.42) was greater than that (36.2 to 50.3) reported for ceramic and plastic brackets [34], although the color values $\left(a^{*},-0.50\right.$ to $-0.41 ; b^{*}, 6.12$ to 8.12) for the BG coating layers were similar with published values $\left(a^{*},-1.3\right.$ to $3.8 ; b^{*},-2.9$ to 11.2) [34]. The color for orthodontic appliances, such as brackets and archwires, should ideally match that of natural teeth, although natural tooth color varies according to race, gender, and age [35]. A previous study measured the CIE $L^{*} a^{*} b^{*}$ color values for the Vita Lumin Vacuum shade guide (A3.5, B1, B3, C4), which is the color selection scale most widely used in dentistry; the values ranged from 43.2 to 61.4 for $L^{*}$, from -1.6 to 6.8 for $a^{*}$, and from 13.2 to 28.8 for $b^{*}$. The $L^{*}$ and $a^{*}$ values from the present 
study are fairly similar, although our mean $b^{*}$ value was smaller than that of the Vita Lumin Vacuum shade guide. Thus, the BG coatings formed by the EPD process in the present study likely produced a clinically acceptable color appearance, but further research is warranted to fine-tune the color.

SEM observations showed that the thickness of the BG coating layers were similar in both specimens coated with AC and DC. However, surface-sensitive parallel-beam XRD analysis revealed that the peaks at $2 \theta=43.5^{\circ}$ and $51.0^{\circ}$ associated with the austenite $(\gamma-\mathrm{Fe})$ phase of the bulk substrate were observed for the BG-coated specimens when DC (DC $15 \mathrm{~V})$ was used. This suggested that the BG coating layer that formed on the specimen using DC had a too-low density. On the other hand, the XRD pattern obtained for thin BG coating layer formed on the specimen using AC (AC $15 \mathrm{~V}$ ) indicated a completely amorphous phase, even for thinner BG coating layers, which suggested that thin BG coating layers formed using AC had better quality with high density. This difference in crystallinity is because undesired electrolysis of water at the electrodes occurred with the DC, which entrapped the coating and degraded the coating quality [36]. This was partly confirmed by the nano-indentation test results, which found that the elastic modulus of the BG layers formed by AC were significantly higher than those of the BG layers formed using DC.

The frictional force between the bracket and the archwire during tooth movement is a primary issue in orthodontics. If the frictional force can be decreased, then the efficiency of tooth movement can be improved $[37,38]$. The frictional properties are attributed to multiple factors, such as surface roughness, hardness, elastic modulus, and the cross-sectional dimensions of the orthodontic wires and brackets $[37,38]$. A recent study reported that commercially available esthetic coating wire influences the frictional properties [15] and the esthetic polymer coating may increase the frictional resistance due to increased wire-binding at the edge of the bracket. The progressive load scratch test used in the present study showed that the BG-coated specimens (DC $15 \mathrm{~V}$ ) displayed significantly higher frictional forces than the other BG-coated specimens (DC $10 \mathrm{~V}$; AC 10 and $15 \mathrm{~V}$ ), although the other BG-coated specimens produced slightly higher frictional forces compared with the non-coated stainless steel specimen. The stainless steel wire alloy generally generates lower levels of frictional resistance than coated wires [15], and the BG-coated specimens, in some conditions, displayed frictional performance that was similar to that of the non-coated stainless steel specimens. Thus, the BG coating can likely provide acceptable clinical frictional characteristics. Evaluation of specimens with thin, high elastic modulus coatings are required to fully explore this aspect.

The results of this study showed that BG-coated specimens had significant acid-neutralizing capability due to their ability to release various ions. This suggests that the BG layer may be able to mitigate enamel demineralization $[39,40]$. Additionally, this in vitro study demonstrated that remineralization of etched enamel was accelerated for the BG-coated specimens, which is the most important finding of the present study. Nano-indentation testing with a $100-\mathrm{mN}$ load showed that the hardness recovered by $49 \%-60 \%$, and elastic modulus by $77 \%-84 \%$, after 3 months of immersion. In comparison, the recovery of the mechanical properties of the etched enamel surface of non-coated specimens was unremarkable: The hardness recovered by $13 \%$ and the elastic modulus by $15 \%$, although artificial saliva contains the inorganic ions necessary for remineralization [41]. A similar trend was observed for the mechanical properties of the top surface regions measured by nano-indentation testing with a 10-mN load (ca. 1000-nm depth analysis).

BG with an amorphous structure can release multiple ions into the oral environment [22-25], which may help to prevent the demineralization of tooth surfaces surrounding brackets and enhance remineralization after bracket debonding. In the present study, XRD analysis confirmed that the EPD coating process had little influence on the crystal structure of the BG coatings, and these enhanced enamel remineralization. However, the BG coatings slightly increased the frictional force. The BG coating formed using AC had acceptable quality and a completely amorphous structure, favorable esthetic character and mechanical properties. Thus, AC may be more suitable for the EPD coating process, although there was no significant difference between the BG-coated specimens formed by DC and AC in terms of their enamel remineralization ability. EPD as a new BG coating process in the 
present study can possibly produce acid-neutralizing and remineralizing capabilities of the enamel surfaces around orthodontic appliances. Further research to optimize the EPD coating conditions is warranted.

\section{Conclusions}

The surface modification technique using EPD and BG for orthodontic stainless steel offers the possibility of developing new orthodontic metallic appliances with satisfactory esthetic appearance and remineralization ability, without being cytotoxic.

Acknowledgments: The authors thank Masataka Fukuchi at Yokohama City Industrial Technical Support Center for his expert technical assistance with the progressive load scratch test. The authors also thank Kazuki Sobue and Takashi Murakami at Shimadzu Corporation for lending their expertise on the application of color measurement. This study was partially supported by a Grant-in-Aid Scientific Research from the Ministry of Education, Culture, Sports, Science and Technology, Japan (No. 25463195).

Author Contributions: Masahiro Iijima conceived and designed the experiments; Kyotaro Kawaguchi and Masahiro Iijima performed the experiments; Masahiro Iijima, Kazuhiko Endo, and Itaru Mizoguchi wrote the paper.

Conflicts of Interest: The authors declare no conflict of interest.

\section{References}

1. Iijima, M.; Zinelis, S.; Papageorgiou, S.N.; Brantley, W.; Eliades, T. Orthodontic brackets. In Orthodontic Application of Biomaterials; Eliades, T., Brantley, W., Eds.; Woodhead Publishing: Sawston, UK, 2017; pp. 75-96.

2. Iijima, M.; Muguruma, T.; Brantley, W.; Choe, H.C.; Nakagaki, S.; Alapati, S.B.; Mizoguchi, I. Effect of coating on properties of esthetic orthodontic nickel-titanium wires. Angle Orthod. 2012, 82, 319-325. [CrossRef] [PubMed]

3. Lopes Filho, H.; Maia, L.E.; Araújo, M.V.; Ruellas, A.C. Influence of optical properties of esthetic brackets (color, translucence, and fluorescence) on visual perception. Am. J. Orthod. Dent. Orthop. 2012, 141, 460-467. [CrossRef] [PubMed]

4. Karamouzos, A.; Athanasiou, A.E.; Papadopoulos, M.A. Clinical characteristics and properties of ceramic brackets: A comprehensive review. Am. J. Orthod. Dent. Orthop. 1997, 112, 34-40. [CrossRef]

5. Alrejaye, N.; Pober, R.; Giordano, I.R. Torsional strength of computer-aided design/computer-aided manufacturing-fabricated esthetic orthodontic brackets. Angle Orthod. 2017, 87, 125-130. [CrossRef] [PubMed]

6. Imai, T.; Yamagata, S.; Watari, F.; Kobayashi, M.; Nagayama, K.; Toyoizumi, H.; Uga, M.; Nakamura, S. Temperature-dependence of the mechanical properties of FRP orthodontic wire. Dent. Mater. J. 1999, 18, 167-175. [CrossRef] [PubMed]

7. Zufall, S.W.; Kusy, R.P. Sliding mechanics of coated composite wires and the development of an engineering model for binding. Angle Orthodont. 2000, 70, 34-47. [PubMed]

8. Burstone, C.J.; Liebler, S.A.H.; Goldberg, A.J. Polyphenylene polymers as esthetic orthodontic archwires. Am. J. Orthod. Dent. Orthop. 2011, 139, e391-e398. [CrossRef] [PubMed]

9. Tanimoto, Y.; Inami, T.; Yamaguchi, M.; Nishiyama, N.; Kasai, K. Preparation, mechanical, and in vitro properties of glass fiber-reinforced polycarbonate composites for orthodontic application. J. Biomed. Mater. Res. B 2015, 103, 743-750. [CrossRef] [PubMed]

10. Da Silva, D.L.; Mattos, C.T.; Simão, R.A.; De Oliveira Ruellas, A.C. Coating stability and surface characteristics of esthetic orthodontic coated archwires. Angle Orthod. 2013, 83, 994-1001. [CrossRef] [PubMed]

11. Da Silva, D.L.; Mattos, C.T.; Sant'Anna, E.F.; Ruellas, A.C.; Elias, C.N. Cross-section dimensions and mechanical properties of esthetic orthodontic coated archwires. Am. J. Orthod. Dent. Orthop. 2013, 143, S85-S91. [CrossRef] [PubMed]

12. Bradley, T.G.; Berzins, D.W.; Valeri, N.; Pruszynski, J.; Eliades, T.; Katsaros, C. An investigation into the mechanical and aesthetic properties of new generation coated nickel-titanium wires in the as-received state and after clinical use. Eur. J. Orthod. 2014, 36, 290-296. [CrossRef] [PubMed] 
13. Kim, I.H.; Park, H.S.; Kim, Y.K.; Kim, K.H.; Kwon, T.Y. Comparative short-term in vitro analysis of mutans streptococci adhesion on esthetic, nickel-titanium, and stainless-steel arch wires. Angle Orthod. 2014, 84, 680-686. [CrossRef] [PubMed]

14. Rudge, P.; Sherriff, M.; Bister, D. A comparison of roughness parameters and friction coefficients of aesthetic archwires. Eur. J. Orthod. 2015, 49-55. [CrossRef] [PubMed]

15. Muguruma, T.; Iijima, M.; Yuasa, T.; Kawaguchi, K.; Mizoguchi, I. Characterization of the coatings covering esthetic orthodontic archwires and their influence on the bending and frictional properties. Angle Orthod. 2017, 87, 610-617. [CrossRef] [PubMed]

16. Newman, G.V. Epoxy adhesives for orthodontic attachments: progress report. Am. J. Orthod. Dent. Orthop. 1965, 51, 901-912. [CrossRef]

17. Eliades, T. Orthodontic materials research and applications: Part 1. Current status and projected future developments in bonding and adhesives. Am. J. Orthod. Dent. Orthop. 2006, 130, 445-451. [CrossRef] [PubMed]

18. Iijima, M.; Muguruma, T.; Brantley, W.A.; Ito, S.; Yuasa, T.; Saito, T.; Mizoguchi, I. Effect of bracket bonding on nanomechanical properties of enamel. Am. J. Orthod. Dent. Orthop. 2010, 138, 735-740. [CrossRef] [PubMed]

19. Feathestone, J.D. Remineralization, the natural caries repair process-The need for new approaches. Adv. Dent. Res. 2009, 21, 4-7. [CrossRef] [PubMed]

20. Tschoppe, P.; Zandim, D.L.; Martus, P.; Kielbassa, A.M. Enamel and dentin remineralization by nano-hydroxyapatite toothpaste. J. Dent. 2011, 39, 430-437. [CrossRef] [PubMed]

21. Hench, L.L.; Hench, L.L.; Splinter, R.J.; Allen, W.C.; Greenlee, T.K. Bonding mechanisms at the interface of ceramic prosthetic materials. J. Biomed. Mater. Res. 1971, 5, 117-141. [CrossRef]

22. Kokubo, T. Apatite formation on surface of ceramics, metals and polymers in body environment. Acta Mater. 1998, 46, 2519-2527. [CrossRef]

23. Hoppe, A.; Güldal, N.S.; Boccaccini, A.R. A review of the biological response to ionic dissolution products from bioactive glasses and glass-ceramics. Biomaterials 2011, 32, 2757-2774. [CrossRef] [PubMed]

24. Fredholm, Y.C.; Karpukhina, N.; Brauer, D.S.; Jones, J.R.; Law, R.V.; Hill, R.G. Influence of strontium for calcium substitution in bioactive glasses on degradation, ion release and apatite formation. J. R. Soc. Interface 2012, 9, 880-889. [CrossRef] [PubMed]

25. Liu, J.; Rawlinson, S.C.; Hill, R.G.; Fortune, F. Fluoride incorporation in high phosphate containing bioactive glasses and in vitro osteogenic, angiogenic and antibacterial effects. Dent. Mater. 2016, 32, 412-422. [CrossRef] [PubMed]

26. Fernandes, J.S.; Gentile, P.; Pires, R.A.; Reis, R.L.; Hatton, P.V. Multifunctional bioactive glass and glass-ceramic biomaterials with antibacterial properties for repair and regeneration of bone tissue. Acta Biomater. 2017, 59, 2-11. [CrossRef] [PubMed]

27. Besra, L.; Liu, M. A review on fundamentals and applications of electrophoretic deposition (EPD). Prog. Mater. Sci. 2007, 52, 1-61. [CrossRef]

28. Chen, Q.; Garcia, R.P.; Munoz, J.; Pérez de Larraya, U.; Garmendia, N.; Yao, Q.; Boccaccini, A.R. Cellulose nanocrystals-Bioactive glass hybrid coating as bone substitutes by electrophoretic co-deposition: In situ control of mineralization of bioactive glass and enhancement of osteoblastic performance. ACS Appl. Mater. Interfaces 2015, 7, 24715-24725. [CrossRef] [PubMed]

29. Commission International de L'Eclairage. Colormetry-Technical Report CIE Pub. No. 15, 3rd ed.; Bureau Central de la CIE: Vienna, Austria, 2004.

30. ISO 14577-1 Metallic Materials_Instrumented Indentation Test for Hardness and Materials Parameters-Part 1: Test Method; International Organization for Standardization: Geneva, Switzerland, 2002.

31. Oliver, W.C.; Pharr, G.M. An improved technique for determining hardness and elastic modulus using load and displacement sensing indentation experiments. J. Mater. Res. 1992, 7, 1564-1583. [CrossRef]

32. Rho, J.Y.; Pharr, G.M. Nanoindentation testing of bone. In Mechanical Testing of Bone and the Bone-Implant Interface; An, Y.H., Draughn, R.A., Eds.; CRC Press: Boca Raton, FL, USA, 1999; pp. 257-269.

33. Iijima, M.; Muguruma, T.; Brantley, W.A.; Mizoguchi, I. Comparisons of nanoindentation, 3-point bending, and tension tests for orthodontic wires. Am. J. Orthod. Dent. Orthop. 2011, 140, 65-71. [CrossRef] [PubMed]

34. Lee, Y.K. Colour and translucency of tooth-colored orthodontic brackets. Eur. J. Orthod. 2008, 30, $205-210$. [CrossRef] [PubMed] 
35. Esan, T.A.; Olusile, A.O.; Akeredolu, P.A. Factors influencing tooth shade selection for completely edentulous patients. J. Contemp. Dent. Pract. 2006, 7, 80-87. [PubMed]

36. Seuss, S.; Lehmann, M.; Boccaccini, A.R. Alternating current electrophoretic deposition of antibacterial bioactive glass-chitosan composite coatings. Int. J. Mol. Sci. 2014, 15, 12231-12242. [CrossRef] [PubMed]

37. Kusy, R.P.; Tobin, E.J.; Whitley, J.Q.; Sioshansi, P. Frictional coefficients of ion-implanted alumina against ion-implanted beta-titanium in the low load, low velocity, single pass regime. Dent. Mater. 1992, 8, 167-172. [CrossRef]

38. Burrow, S.J. Friction and resistance to sliding in orthodontics: A critical review. Am. J. Orthod. Dent. Orthop. 2009, 135, 442-447. [CrossRef] [PubMed]

39. Hu, W.; Featherstone, J.D. Prevention of enamel demineralization: An in-vitro study using light-cured filled sealant. Am. J. Orthod. Dent. Orthop. 2005, 128, 592-600. [CrossRef] [PubMed]

40. Gorton, J.; Featherstone, J.D. In vivo inhibition of demineralization around orthodontic brackets. Am. J. Orthod. Dentofacial Orthop. 2003, 123, 10-14. [CrossRef] [PubMed]

41. De Almeida, P.D.V.; Grégio, A.M.; Machado, M.A.; de Lima, A.A.; Azevedo, L.R. Saliva composition and functions: A comprehensive review. J. Contemp. Dent. Pract. 2008, 9, 72-80.

(C) 2017 by the authors. Licensee MDPI, Basel, Switzerland. This article is an open access article distributed under the terms and conditions of the Creative Commons Attribution (CC BY) license (http:/ / creativecommons.org/licenses/by/4.0/). 